\title{
Blood pressure control to prevent decline in cognition after stroke
}

\author{
This article was published in the following Dove Press journal: \\ Vascular Health and Risk Management \\ 9 June 2015 \\ Number of times this article has been viewed
}

\section{Hege Ihle-Hansen' \\ Bente Thommessen ${ }^{2}$ \\ Morten W Fagerland ${ }^{3}$ \\ Anne R Øksengård ${ }^{4}$ \\ Torgeir B Wyller ${ }^{5}$ \\ Knut Engedal ${ }^{6}$ \\ Brynjar Fure ${ }^{7}$}

'Department of Internal Medicine, Vestre Viken Hospital Trust,

Bærum Hospital, Bærum, Norway;

${ }^{2}$ Department of Neurology,

Akershus University Hospital, Lørenskog, Norway; ${ }^{3}$ Oslo Centre for Biostatistics and Epidemiology, Research Support Services, Oslo University Hospital, Norway; ${ }^{4}$ Department of Internal medicine, Vestre Viken Hospital Trust, Bærum Hospital, Bærum, Norway; ${ }^{5}$ Department of Geriatric Medicine, Oslo University Hospital, Oslo, Norway; ${ }^{6}$ Norwegian Centre for Dementia Research, Oslo University Hospital, Oslo, Norway; ${ }^{7}$ Norwegian Knowledge Centre for the Health Services, Oslo, Norway
Correspondence: Hege Ihle-Hansen Department of Internal Medicine, Vestre Viken Hospital Trust, Bærum Hospital, 3004 Drammen, Norway Tel +47 4I443866

Email hege.ihle-hansen@vestreviken.no
Background: Treatment of hypertension post-stroke preserves cognition through prevention of recurrent stroke, but it is not clear whether it prevents cognitive decline through other mechanisms. We aimed to describe changes in blood pressure from baseline to 1 year post-stroke and to evaluate the association between achieved blood pressure targets and cognitive function, mild cognitive impairment (MCI), and dementia.

Methods: We included patients with first-ever stroke, and defined achieved blood pressure goals as systolic blood pressure (SBP) in the categories $\leq 125 \mathrm{mmHg}, \leq 140 \mathrm{mmHg}$, and $\leq 160 \mathrm{mmHg}$, SBP reduction of $\geq 10 \mathrm{mmHg}$, and diastolic blood pressure (DBP) reduction of $\geq 5 \mathrm{mmHg}$. The main outcome variables were cognitive assessments 1 year post stroke. Secondary outcomes were diagnoses of MCI or dementia.

Results: Forty-one of 166 patients (25\%) reached SBP $\leq 125 \mathrm{mmHg}$ after 1 year, 92/166 (55\%) reached $\mathrm{SBP} \leq 140 \mathrm{mmHg}$, and 150/166 (90\%) reached SBP $\leq 160 \mathrm{mmHg}$. SBP was reduced by $\geq 10 \mathrm{mmHg}$ in $44 / 150$ (29\%) and DBP by $\geq 5 \mathrm{mmHg}$ in $57 / 150$ (38\%). We did not find any statistically significant associations between cognitive test performances and different blood pressure goals $(P=0.070-1.0)$. Nor was there any significant association between achieved goal blood pressure or blood pressure reduction after 1 year and the diagnoses of MCI or dementia $(P=0.32-0.56)$.

Conclusion: Treatment of hypertension is important for primary and secondary prevention of stroke. Showing a potential beneficial effect of blood pressure control on cognitive function, however, probably needs longer follow-up.

Keywords: cognitive impairment, hypertension, cerebrovascular disease, risk factor management, secondary prevention

\section{Background}

Vascular diseases with and without stroke contribute to cognitive impairment and dementia, and may lead to vascular cognitive impairment, Alzheimer's disease, or a mixed condition of Alzheimer's disease and cerebrovascular disorder. ${ }^{1,2}$ Post-stroke cognitive impairments include the continuum from milder cognitive deficits to severe dementia, affect different cognitive domains, and are caused by both degenerative and vascular pathologies. Larger infarct volumes and increased number of infarcts are associated with cognitive problems and dementia. ${ }^{3}$ The actual stroke lesion and complications in the acute phase may affect cognition in the early period after stroke, but how a single stroke may lead to progression of cognitive impairment is unclear. One explanation might be that vascular dysfunction progresses and has a large impact over years after the stroke, but this is not likely to be the only explanation. 
Hypertension is a known risk factor for stroke, cardiovascular disease, ${ }^{4}$ white matter hyperintensities, and cognitive decline and dementia due to vascular dementia and Alzheimer's disease. ${ }^{5,6}$ Antihypertensive drug treatment reduces the risk of stroke and cardiovascular disease, ${ }^{7,8}$ and may reduce the risk of dementia, although the evidence for the latter is poor. ${ }^{9-11}$ Lowering of blood pressure is effective for prevention of recurrent stroke, but the optimal target or reduction is unknown. ${ }^{12}$ Today, guidelines regarding secondary prevention after stroke recommend an individualized blood pressure target and a reduction of approximately $10 / 5 \mathrm{mmHg}$ or below $140 / 90 \mathrm{mmHg} \cdot{ }^{13,14}$

Effective measures to slow down the cognitive decline post stroke are urgently needed. ${ }^{15}$ There is no clear evidence that lowering the blood pressure post stroke will lead to better cognition or prevent a decline in cognition or development of dementia. ${ }^{16}$ The recently published SPS3 study did not report any significant effect of blood pressure reduction on cognition in patients with lacunar stroke. ${ }^{12,17}$ The aims of the present study were to describe changes in blood pressure from baseline to 1 year post stroke, and to test the hypothesis that patients who achieve the blood pressure targets have a better cognitive outcome and more rarely develop mild cognitive impairment (MCI) or dementia than patients who do not achieve blood pressure targets.

\section{Methods}

\section{Study population}

Patients with a first-ever stroke admitted to the in-patient stroke unit of Bærum Hospital between February 2007 and July 2008 were invited to participate in a randomized controlled trial (RCT). The study was registered in Clinicaltrials.gov (NCT00506818). Change in cognition was the primary endpoint in the study reported previously. ${ }^{18}$ The RCT was negative, and in the present secondary study we evaluate the association between achieved blood pressure and blood pressure reduction on one side and cognitive outcomes on the other, regardless of the allocation in the RCT.

For the present analysis, we excluded patients with transient ischemic attack (TIA), subarachnoid hemorrhage, pre-stroke cognitive impairment as indicated by a score $\geq 3.7$ on the Informant Questionnaire on Cognitive Decline in the Elderly (IQCODE) ${ }^{19}$ previous stroke or TIA, patients who did not speak Norwegian, and patients with a remaining life expectancy of less than 1 year as estimated by the treating physician.

\section{Baseline data}

Vascular risk factors recorded at baseline included treated hypertension before hospitalization, hyperlipidemia (total cholesterol $>5.0 \mathrm{mmol} / \mathrm{L}$ or low-density lipoprotein cholesterol $>3.0 \mathrm{mmol} / \mathrm{L}$ ), diabetes mellitus, atrial fibrillation (permanent or paroxysmal), current smoking, waist and hip circumferences, and calculated waist-to-hip-ratio.

Blood pressure was measured daily during the morning round, with the patient in the supine position, after a minimum 5 minutes' rest. In the analyses, we used the blood pressure measured on day 3 after admittance to the hospital. Pre-stroke cognitive impairment was screened for by the 26-question version of the IQCODE. When possible, the questionnaire was filled in by first-degree relatives. Cognitive function was measured between day 3 and 7 after admittance, with the Mini Mental State Examination, ${ }^{20} \mathrm{Clock}$ Drawing Test, ${ }^{21}$ Trail Making Test (TMT) A and B, and the immediate and delayed recall parts of the 10-word memory test (minimum score 0 and maximum 40). ${ }^{22,23}$ Anxiety and depressive symptoms were evaluated using the Hospital Anxiety and Depression Scale (HADS) ${ }^{24}$ The patients were genotyped for apolipoprotein E (Apo E 4) alleles.

Neurological impairments were measured by the National Institute of Health Stroke Scale (NIHSS) by a stroke physician. ${ }^{25}$ Activities of daily living (ADL) were assessed at discharge by stroke nurses using the Barthel ADL index. ${ }^{26}$ The stroke was classified according to the Oxfordshire Community Stroke Project classification, and patients with ischemic stroke were classified according to The Trial of Org 10172 in Acute Stroke Treatment classification at discharge. ${ }^{27,28}$

\section{Follow-up data}

Follow-up was performed 12 months after the stroke event. Assessments for cognitive, emotional, neurological, and functional status were repeated. Blood pressure was measured in the supine position after 5 minutes' rest. Self-reported physical activity was recorded.

\section{Intervention, control conditions, and assessment of the outcome}

Hypertension was treated through lifestyle and pharmacological interventions according to guidelines recommending a blood pressure below 140/90 mmHg..$^{29}$ All antihypertensive therapeutic agents could be used in the intervention group, and dose adjustments were made and additional antihypertensive drugs were administered when the blood pressure was higher than 140/90 $\mathrm{mmHg}$, unless the patients suffered 
from severe large-vessel disease. The controls received care as usual.

The main outcome variables were defined as cognitive functions as measured by one or more of the tests for different cognitive domains 1 year post stroke. The secondary outcomes were diagnoses of MCI or dementia also 1 year post stroke.

\section{Ethics}

The study was approved by the Regional Committee for Ethics in Medical Research and by the Data Protection Authorities. All patients gave their written informed consent before inclusion. First-degree relatives gave consent on behalf of patients with reduced capacity.

\section{Statistics}

The associations between the cognitive test performances (outcome variables) and the explanatory variables achieved blood pressure goals (systolic blood pressure [SBP] in the categories $\leq 125 \mathrm{mmHg}, \leq 140 \mathrm{mmHg}$, and $\leq 160 \mathrm{mmHg}$, respectively, SBP reduction of $\geq 10 \mathrm{~mm} \mathrm{Hg}$, and diastolic blood pressure [DBP] reduction of $\geq 5 \mathrm{~mm} \mathrm{Hg}$ ) were studied using linear regression for the outcomes TMT A and B, the 10-word test and Mini Mental State Examination, and logistic regression for the outcome Clock Drawing Test. For each combination of outcome and explanatory variable, two models were fitted: one univariate (unadjusted) model, and one model adjusted for 17 possible confounding variables: age, sex, education, Apo E alleles, hyperlipidemia, diabetes, atrial fibrillation, coronary heart disease, current smoking, hip-waist-ratio, physical activity, neurological deficits as measured by NIHSS day 1, IQCODE, HADS, Oxfordshire Community Stroke Project, Barthel ADL index, and stroke type. Only variables measured at baseline, except physical activity from the follow-up, were included as adjustment variables. The statistical analyses were performed with Stata version 13 (StataCorp LP).

\section{Clinical trial registration information}

ClinicalTrials.gov, number NCT00506818.

\section{Results \\ Baseline characteristics}

The initial study population consisted of 250 patients with stroke or TIA. Of these, 59 were excluded from these analyses, 48 did not fulfill the inclusion criteria (36 had a TIA, 6 had an IQCODE score $\geq 3.7,1$ did not speak Norwegian,
1 had an infarction in the spinal cord, 1 had suffered a previous TIA, 2 withdrew their consent, and 1 died before signing the consent), and 11 were diagnosed with other disease than stroke.

Of the remaining 191 patients, 166 completed the follow-up. Of the 25 patients missing, 17 died (three due to a recurrent stroke), six refused to complete follow-up, and two had missing data regarding blood pressure. Of the 166 patients having blood pressure measurements and cognitive screening at follow-up, $149(90 \%)$ had a cerebral infarction and $17(10 \%)$ had a cerebral hemorrhage. Five patients suffered a new TIA during follow-up. Sixteen did not have baseline measures of blood pressure, 13 were already discharged, and three had missing values of unknown causes. Thus, the study sample comprised 166 patients; whereas the analyses on change in blood pressure included 150 patients.

Baseline characteristics of the study population are shown in Table 1. Mean age was 71.5 \pm 12.4 (range: $25-94$ years) and $56 \%$ were men. At baseline, the mean SBP was 138.0 \pm 24.6 (range: 79-211 $\mathrm{mmHg}$ ).

\section{Blood pressure at 12 months post stroke}

Overall, there was a mean increase in SBP from baseline to 1-year follow-up by $0.53 \mathrm{mmHg}$ (95\% CI -3.8 to 4.9$)$. Only 64 of 150 patients $(43 \%)$ had a reduction in $\mathrm{mmHg}$ of SBP from baseline to 12-month follow-up, and 88 of 150 patients $(59 \%)$ had a reduction in DBP.

In all, 41 of 166 patients (25\%) reached $\mathrm{SBP} \leq 125 \mathrm{mmHg}$ after 1 year, 92/166 (55\%) reached $\mathrm{SBP} \leq 140 \mathrm{mmHg}$, and $150 / 166(90 \%)$ reached $\mathrm{SBP} \leq 160 \mathrm{mmHg}$. SBP was reduced by $\geq 10 \mathrm{mmHg}$ in $44 / 150(29 \%)$ and $\mathrm{DBP}$ by $\geq 5 \mathrm{mmHg}$ in $57 / 150(38 \%)$.

\section{Blood pressure targets and cognitive outcomes}

As shown in Table 2, we did not find any significant associations between cognitive test performances (outcome variables) and different blood pressure goals ( $P=0.070-1.0)$. Forty patients (24\%) were diagnosed with MCI and 61 patients $(37 \%)$ with dementia. There was no significant association between the achieved goal blood pressure or blood pressure reduction after 1 year and the diagnoses of MCI or dementia $(P=0.32-0.56)$.

\section{Discussion}

Previous studies have shown that patients suffering from a stroke have an increased risk of a decline of cognitive symptoms 
Table I Patient description $(n=166)$

\begin{tabular}{|c|c|c|}
\hline Assessment & $\begin{array}{l}\text { Baseline } \\
(\mathrm{N}=97)\end{array}$ & 12 months \\
\hline \multicolumn{3}{|l|}{ Demographics } \\
\hline Men & $93(56)$ & \\
\hline Mean age, years (SD) & $71.5(12.4)$ & \\
\hline Less than 9 years of education & $37(22)$ & \\
\hline \multicolumn{3}{|l|}{ Stroke subtype } \\
\hline Cerebral infarction & $149(90)$ & \\
\hline Cerebral hemorrhage & $17(10)$ & \\
\hline \multicolumn{3}{|l|}{ Risk factors } \\
\hline Hypertension & $96(58)$ & \\
\hline Hyperlipidemia & $92(55)$ & \\
\hline Diabetes & $20(12)$ & \\
\hline Cigarette smoking (present) & $39(24)$ & \\
\hline Coronary heart disease & $39(24)$ & \\
\hline Atrial fibrillation & $49(30)$ & \\
\hline Daily alcohol use & $32(24)$ & \\
\hline $\mathrm{BMI}>25$ & $96(58)$ & \\
\hline $\begin{array}{l}\text { Physical activity, minutes } \\
\text { per week (SD) }\end{array}$ & & $183(206)$ \\
\hline Apo E 4 allele & $38(23)$ & \\
\hline \multicolumn{3}{|l|}{ OCSP classification } \\
\hline $\mathrm{TACl}$ & $18(11)$ & \\
\hline $\mathrm{PACl}$ & $78(47)$ & \\
\hline $\mathrm{LACl}$ & $46(28)$ & \\
\hline $\mathrm{POCl}$ & $24(15)$ & \\
\hline \multicolumn{3}{|l|}{ TOAST classification } \\
\hline Large-vessel disease & $19(13)$ & \\
\hline Cardio embolic disease & $45(30)$ & \\
\hline Small-vessel disease & $48(32)$ & \\
\hline Stroke of undetermined etiology & $37(25)$ & \\
\hline \multicolumn{3}{|l|}{ Precerebral arteries } \\
\hline $\begin{array}{l}\text { Internal carotid artery } \\
\text { disease } \geq 50 \%\end{array}$ & $22(13)$ & \\
\hline Vertebral artery occlusion & $5(3)$ & \\
\hline \multicolumn{3}{|l|}{ Antihypertensive medication } \\
\hline Betablocker & & $69(42)$ \\
\hline ACE inhibitor & & $37(22)$ \\
\hline Angiotensin II receptor blocker & & $47(28)$ \\
\hline Calcium antagonist & & $36(22)$ \\
\hline Diuretics & & $54(33)$ \\
\hline \multicolumn{3}{|c|}{ Number of antihypertensive medication } \\
\hline 0 & & $40(24)$ \\
\hline I & & $5 I(3 I)$ \\
\hline 2 & & $4 \mid(25)$ \\
\hline 3 & & $22(13)$ \\
\hline 4 & & $12(7)$ \\
\hline \multicolumn{3}{|l|}{ Assessments } \\
\hline $\begin{array}{l}\text { Systolic blood pressure, } \\
\text { supine position (SD) }\end{array}$ & $138.0(24.6)^{*}$ & I38.3 (|8.8) \\
\hline Median (IQR) & $135.5(|2|-\mid 57)$ & $137.0(\mid 25-152)$ \\
\hline $\begin{array}{l}\text { Diastolic blood pressure, } \\
\text { supine position (SD) }\end{array}$ & $80.3(14.4)^{*}$ & $75.4(10.6)$ \\
\hline Median (IQR) & $78(71.0-89.3)$ & $76.0(67.0-83.0)$ \\
\hline NIHSS, median (IQR) & $1.0(0-2)^{* *}$ & $1.0(0-2)$ \\
\hline $\mathrm{BI}$, median (IQR) & $20(18-20)$ & $20(19-20)$ \\
\hline mRS, median (IQR) & $I(I-2)$ & $I(I-2)$ \\
\hline IQCODE (SD)*** & $3.10(0.22)$ & $3.3(0.4 \mathrm{I})$ \\
\hline
\end{tabular}

(Continued)
Table I (Continued)

\begin{tabular}{lll}
\hline Assessment**** & $\begin{array}{l}\text { Baseline } \\
(\mathbf{N}=97)\end{array}$ & I 2 months \\
\hline MMSE (SD) & $25.6(4.6)$ & $25.7(5.8)$ \\
TMT A (SD) & $78.3(71.8)$ & $66.9(5 I .0)$ \\
TMT B (SD) & $157.0(86.7)$ & $147.0(85.3)$ \\
I0-word test (SD) & $21.0(7.3)$ & $23.1(8.6)$ \\
Clock Drawing Test, correct & $89(53.6)$ & $96(57.8)$ \\
HADS total & $7.5(5.8)$ & $6.9(5.3)$ \\
\hline
\end{tabular}

Notes: Figures are in $\mathrm{n}(\%)$ unless specified otherwise. Hyperlipidemia denotes total cholesterol $>5 \mathrm{mmol} / \mathrm{L}$ or LDL-cholesterol $>3 \mathrm{mmol} / \mathrm{L}$. Coronary heart disease means previous myocardial infarction or present angina pectoris. Atrial fibrillation denotes permanent or paroxysmal atrial fibrillation. Anxiety and depressive symptoms were evaluated using HADS. ${ }^{n}=150$; **NIHSS at discharge; *** $n=118-166$ due to missing values in cognitive and emotional assessments.

Abbreviations: LDL, low-density lipoprotein; BMI, body mass index; Apo E 4, apolipoprotein E alleles; OCSP, Oxfordshire Community Stroke Project; TACl, total anterior circulation infarction; $\mathrm{PACl}$, partial anterior circulation infarction; $\mathrm{LACl}$, lacunar circulation infarction; $\mathrm{POCl}$, posterior circulation infarction; TOAST, The Trial of Org 10172 in Acute Stroke Treatment; NIHSS, National Institute of Health Stroke Scale; IQR, interquartile range; BI, Barthel Activities of Daily Living Index; mRS, modified Rankin Scale; IQCODE, Informant Questionnaire on Cognitive Decline in the Elderly; MMSE, Mini Mental State Examination; TMT A, trail making test A; TMT B, trail making test B. HADS, Hospital Anxiety and Depression Scale.

years after the stroke event., ${ }^{2,30}$ The mechanisms involved are not fully known, but treating vascular risk has been proposed as a possible measure to prevent a decline in cognition. In this study, we evaluated the association between blood pressure control and cognitive function 1 year after a stroke. We did not find any significant associations on cognitive performance, $\mathrm{MCI}$, or dementia by treating blood pressure. Even in the patients with SBP below $125 \mathrm{mmHg}$, we found no beneficial effect.

The lack of effect may be explained by the fact that the majority of the patients did not have a very high blood pressure at baseline. Half of them had higher blood pressure 1 year post stroke compared to baseline, and only one-third achieved the recommended individualized reduction of $10 \mathrm{mmHg}$ in SBP. Unfortunately, we had only one measure of blood pressure at every assessment, and not the average of 24 hours. When this study was planned, the recommended goal for blood pressure control was $<140 / 90 \mathrm{mmHg} .{ }^{29} \mathrm{The}$ guidelines advise individualized blood pressure achievement with reduction of 10/5 mmHg or below 140/90 mmHg. ${ }^{13,14}$

Cognitive impairment post stroke can probably partly be explained as a stable rest phenomenon related to the actual stroke lesion. Treatment of blood pressure post stroke may have little impact in these patients due to minimal reversibility. The potential effect of controlling blood pressure post stroke may be associated with chronic vascular disease and subsequent progressive cognitive impairment. These changes develop over decades, and the effect of good blood pressure management may have potential impact over several years and later in the post-stroke period. 
Table 2 Results of unadjusted and adjusted regression models for associations between achievement of different blood pressure targets and cognitive test performances (outcome variables)

\begin{tabular}{|c|c|c|c|c|c|}
\hline \multirow{2}{*}{$\begin{array}{l}\text { Explanatory } \\
\text { variables }\end{array}$} & \multicolumn{5}{|c|}{ Cognitive test performance } \\
\hline & TMT A & TMT B & I0-word test & MMSE & Clock Drawing Test* \\
\hline \multicolumn{6}{|l|}{$\mathrm{SBP} \leq 125$} \\
\hline Univariate & $4.20(-14.6,23.0)$ & $-12.8(-47.5,21.9)$ & $-0.72(-3.76,2.32)$ & $0.02(-2.05,2.09)$ & $1.06(0.52,2.15)$ \\
\hline Adjusted** & $0.23(-19.1,19.6)$ & $-20.2(-55.1,14.8)$ & $-0.47(-3.65,2.72)$ & $0.56(-1.20,2.32)$ & $1.25(0.44,3.53)$ \\
\hline \multicolumn{6}{|l|}{$S B P \leq \mid 40$} \\
\hline Univariate & $1.98(-14.5,18.4)$ & $6.91(-22.8,36.6)$ & $-0.74(-3.42,1.94)$ & $0.09(-1.92,1.74)$ & $1.29(0.69,2.42)$ \\
\hline Adjusted** & $2.23(-15.3,19.8)$ & $21.3(-10.8,53.3)$ & $-1.78(-4.70,1.14)$ & $-0.45(-2.06,1.16)$ & $1.96(0.75,5.09)$ \\
\hline \multicolumn{6}{|l|}{$S B P \leq 160$} \\
\hline Univariate & $-23.8(-51.9,4.30)$ & $-21.3(-76.9,34.3)$ & $2.39(-2.19,6.97)$ & $2.04(-0.98,5.07)$ & $0.69(0.25,1.95)$ \\
\hline Adjusted** & $-21.3(-47.8,5.09)$ & $5.74(-44.9,56.4)$ & $-1.24(-5.87,3.38)$ & $0.005(-2.47,2.48)$ & I.95 $(0.45,8.4 I)$ \\
\hline \multicolumn{6}{|c|}{$S B P$ reduction $\geq 10$} \\
\hline Univariate & II.5 (-8.3।, 3|.4) & $0.83(-34.6,36.3)$ & $-0.19(-3.27,2.89)$ & $-0.5 \mathrm{I}(-2.68, \mathrm{I} .66)$ & $1.56(0.77,3.17)$ \\
\hline Adjusted** & $7.32(-13.7,28.4)$ & $-11.7(-49.3,26.0)$ & $-0.77(-4.06,2.5 \mathrm{I})$ & $0.07(-1.92,1.78)$ & $1.79(0.63,5.13)$ \\
\hline \multicolumn{6}{|c|}{ DBP reduction $\geq 5$} \\
\hline Univariate & $-1.88(-18.4,14.6)$ & $4.64(-25.1,34.4)$ & $1.03(-1.68,3.74)$ & $0.58(-1.34,2.50)$ & I. $10(0.59,2.04)$ \\
\hline Adjusted** & $2.08(-15.6,19.8)$ & $12.5(-18.3,43.4)$ & $-0.35(-3.23,2.52)$ & $-0.29(-1.88,1.29)$ & $0.65(0.25,1.70)$ \\
\hline
\end{tabular}

Notes: Data are regression coefficient $(95 \% \mathrm{Cl})$ unless specified otherwise. *Odds ratio; **adjusted for age, sex, education, Apo $\mathrm{E}$ alleles, hyperlipidemia, diabetes, atrial fibrillation, coronary heart disease, current smoking, hip-waist-ratio, physical activity, NIHSS day I, IQCODE (Informant Questionnaire on Cognitive Decline in the Elderly), HADS, OCSP, Barthel ADL index, and stroke type.

Abbreviations: $\mathrm{Cl}$, confidence interval; SBP, systolic blood pressure; DBP, diastolic blood pressure; TMT A, trail making test A; TMT B, trail making test B ; MMSE, Mini Mental State Examination; NIHSS, National Institute of Health Stroke Scale; HADS, Hospital Anxiety and Depression Scale; OCSP, Oxfordshire Community Stroke Project; ADL, Activities of daily living.

The study has limitations. First, the previously reported RCT regarding intensive risk factor management regarding all modifiable risk factor did not find any effect on cognitive outcome, despite good pharmacological adherence to the program in the intervention group. ${ }^{18}$ Second, the findings in the study are from a single center with a limited sample size (and thus a suboptimal statistical power) and a relatively short follow-up period. A larger multicenter study and longer follow-up would have improved generalizability of the findings. Third, blood pressure was measured only once, both at baseline and follow-up, and there is increasing knowledge regarding blood pressure variability. Fluctuations in blood pressure are suggested as a potential risk factor for cognitive decline in patients with degenerative diseases. ${ }^{31}$ In addition, treatment of blood pressure was differentiated and managed according to tolerance and indications in relation to comorbid conditions, resulting in many antihypertensive regimes. Therefore, we were not able to investigate the potential relationship between different antihypertensive drug classes and cognitive outcome in this study. ${ }^{32}$

The study has both research and clinical implications. Treatment of hypertension post-stroke preserves cognition through prevention of a recurrent stroke. Strategies for blood pressure control include both pharmacological and nonpharmacological interventions. Increased long-term mortality in stroke survivors with increased risk factor burden has been observed, ${ }^{33}$ and early identification and treatment of vascular risk factors are of importance to improve the prognosis in stroke, both in primary and secondary prevention. Showing a potential beneficial effect of blood pressure control on cognitive function, however, probably needs longer follow-up.

\section{Acknowledgments}

This work was supported by the Southern and Eastern Norway Regional Health Authority, Medical Research Foundation, Bærum Hospital, and the Vestre Viken Hospital Trust.

\section{Author contributions}

$\mathrm{HI}-\mathrm{H}, \mathrm{BT}$, TBW, MWF, KE, ARØ, and BF were involved in the study design and all part of the preparation of the manuscript; MWF performed the statistical work; and all authors gave the final approval.

\section{Disclosure}

The authors declare no conflicts of interest in this work.

\section{References}

1. Gorelick PB, Scuteri A, Black SE, et al. Vascular contributions to cognitive impairment and dementia: a statement for healthcare professionals from the American heart association/American stroke association. Stroke. 2011;42:2672-2713.

2. Pendlebury ST. Dementia in patients hospitalized with stroke: rates, time course, and clinico-pathologic factors. Int J Stroke. 2012;7:570-581. 
3. Pendlebury ST, Rothwell PM. Prevalence, incidence, and factors associated with pre-stroke and post-stroke dementia: a systematic review and meta-analysis. Lancet Neurol. 2009;8:1006-1018.

4. James PA, Oparil S, Carter BL, et al. 2014 evidence-based guideline for the management of high blood pressure in adults: report from the panel members appointed to the Eighth Joint National Committee (JNC 8). JAMA. 2014;311:507-520.

5. Maillard P, Seshadri S, Beiser A, et al. Effects of systolic blood pressure on white-matter integrity in young adults in the Framingham Heart Study: a cross-sectional study. Lancet Neurol. 2012;11: 1039-1047.

6. Kivipelto M, Ngandu T, Laatikainen T, Winblad B, Soininen H, Tuomilehto J. Risk score for the prediction of dementia risk in 20 years among middle aged people: a longitudinal, population-based study. Lancet Neurol. 2006;5:735-741.

7. Goldstein LB, Bushnell CD, Adams RJ, et al; Council on Cardiovascular Nursing, Council on Epidemiology and Prevention, Council for High Blood Pressure Research, Council on Peripheral Vascular Disease, and Interdisciplinary Council on Quality of Care and Outcomes Research. Guidelines for the primary prevention of stroke: a guideline for healthcare professionals from the American Heart Association/American Stroke Association. Stroke. 2011;42:517-584.

8. Perk J, De Backer G, Gohlke H, et al. European guidelines on cardiovascular disease prevention in clinical practice (version 2012) : the fifth joint task force of the European society of cardiology and other societies on cardiovascular disease prevention in clinical practice (constituted by representatives of nine societies and by invited experts). Int J Behav Med. 2012 Dec;19(4):403-488.

9. Forette F, Seux ML, Staessen JA, et al. Prevention of dementia in randomised double-blind placebo-controlled Systolic Hypertension in Europe (Syst-Eur) trial. Lancet. 1998;352:1347-1351.

10. Tzourio C, Anderson C, Chapman N, et al; PROGRESS Collaborative Group. Effects of blood pressure lowering with perindopril and indapamide therapy on dementia and cognitive decline in patients with cerebrovascular disease. Arch Intern Med. 2003;163:1069-1075.

11. Peters R, Beckett N, Forette F, et al; HYVET investigators. Incident dementia and blood pressure lowering in the Hypertension in the Very Elderly Trial cognitive function assessment (HYVET-COG): a doubleblind, placebo controlled trial. Lancet Neurol. 2008;7:683-689.

12. SPS3 Study Group, Benavente OR, Coffey CS, et al. Blood-pressure targets in patients with recent lacunar stroke: the SPS3 randomised trial. Lancet. 2013;382:507-515.

13. Furie KL, Kasner SE, Adams RJ, et al; American Heart Association Stroke Council, Council on Cardiovascular Nursing, Council on Clinical Cardiology, and Interdisciplinary Council on Quality of Care and Outcomes Research. Guidelines for the prevention of stroke in patients with stroke or transient ischemic attack: a guideline for healthcare professionals from the American heart association/American stroke association. Stroke. 2011;42:227-276.

14. Kernan WN, Ovbiagele B, Black HR, et al. Guidelines for the prevention of stroke in patients with stroke and transient ischemic attack: a guideline for healthcare professionals from the American Heart Association/ American Stroke Association. Stroke. 2014;45:2160-2236.

15. Pollock A, St GB, Fenton M, Firkins L. Top ten research priorities relating to life after stroke. Lancet Neurol. 2012;11:209.
16. Ankolekar S, Geeganage C, Anderton P, Hogg C, Bath PM. Clinical trials for preventing post stroke cognitive impairment. J Neurol Sci. 2010;299:168-174.

17. Jacova C, Pearce LA, Costello R, et al. Cognitive impairment in lacunar strokes: the SPS3 trial. Ann Neurol. 2012;72:351-362.

18. Ihle-Hansen H, Thommessen B, Fagerland MW, et al. Multifactorial vascular risk factor intervention to prevent cognitive impairment after stroke and TIA: a 12-month randomized controlled trial. Int J Stroke. 2014;9(7):932-938.

19. Jorm AF, Jacomb PA. The Informant Questionnaire on Cognitive Decline in the Elderly (IQCODE): socio-demographic correlates, reliability, validity and some norms. Psychol Med. 1989;19: 1015-1022.

20. Folstein MF, Folstein SE, McHugh PR. "Mini-mental state". A practical method for grading the cognitive state of patients for the clinician. J Psychiatr Res. 1975;12:189-198.

21. Eddy JR, Sriram S. Clock-drawing and telling time as diagnostic aids. Neurology. 1977;27:595.

22. Reitan RM. Validity of the trail making test as an indicator of organic brain damage. Percept Mot Skills. 1958;8:271-276.

23. Randolph C, Tierney MC, Mohr E, Chase TN. The Repeatable Battery for the Assessment of Neuropsychological Status (RBANS): preliminary clinical validity. J Clin Exp Neuropsychol. 1998;20: 310-319.

24. Johnson G, Burvill PW, Anderson CS, Jamrozik K, Stewart-Wynne EG, Chakera TM. Screening instruments for depression and anxiety following stroke: experience in the Perth community stroke study. Acta Psychiatr Scand. 1995;91:252-257.

25. Goldstein LB, Bertels C, Davis JN. Interrater reliability of the NIH stroke scale. Arch Neurol. 1989;46:660-662.

26. Sulter G, Steen C, De KJ. Use of the Barthel index and modified Rankin scale in acute stroke trials. Stroke. 1999;30:1538-1541.

27. Bamford J, Sandercock P, Dennis M, Burn J, Warlow C. Classification and natural history of clinically identifiable subtypes of cerebral infarction. Lancet. 1991;337:1521-1526.

28. Adams HP Jr, Bendixen BH, Kappelle LJ, et al. Classification of subtype of acute ischemic stroke. Definitions for use in a multicenter clinical trial. TOAST. Trial of Org 10172 in Acute Stroke Treatment. Stroke. 1993;24:35-41.

29. Smith SC Jr, Allen J, Blair SN, et al. AHA/ACC guidelines for secondary prevention for patients with coronary and other atherosclerotic vascular disease: 2006 update: endorsed by the National Heart, Lung, and Blood Institute. Circulation. 2006;113:2363-2372.

30. Allan LM, Rowan EN, Firbank MJ, et al. Long term incidence of dementia, predictors of mortality and pathological diagnosis in older stroke survivors. Brain. 2011;134:3716-3727.

31. Lattanzi S, Luzzi S, Provinciali L, Silvestrini M. Blood pressure variability predicts cognitive decline in Alzheimer's disease patients. Neurobiol Aging. 2014;35:2282-2287.

32. Chen Y, Copeland WK, Vedanthan R, et al. Association between body mass index and cardiovascular disease mortality in East Asians and south Asians: pooled analysis of prospective data from the Asia Cohort Consortium. BMJ. 2013;347:f5446.

33. Gjerde G, Naess H. Risk factor burden predicts long-term mortality after cerebral infarction. Acta Neurol Scand. 2014;129:173-177.
Vascular Health and Risk Management

\section{Publish your work in this journal}

Vascular Health and Risk Management is an international, peerreviewed journal of therapeutics and risk management, focusing on concise rapid reporting of clinical studies on the processes involved in the maintenance of vascular health; the monitoring, prevention and treatment of vascular disease and its sequelae; and the involvement of
Dovepress

metabolic disorders, particularly diabetes. This journal is indexed on PubMed Central and MedLine. The manuscript management system is completely online and includes a very quick and fair peer-review system, which is all easy to use. Visit http://www.dovepress.com/ testimonials.php to read real quotes from published authors. 